\title{
Often claimed, rarely tested: differences in individual treatment response
}

\author{
Stephanie Winkelbeiner, Ph.D. ${ }^{1,2,3,4}$, Stefan Leucht, M.D. ${ }^{5}$, John M. Kane, M.D. ${ }^{1,2,3}$, \& Philipp Homan, \\ M.D., Ph.D. ${ }^{1,2,3}$ \\ ${ }^{1}$ Center for Psychiatric Neuroscience, Feinstein Institute for Medical Research, Manhasset, NY, USA \\ ${ }^{2}$ Division of Psychiatry Research, Zucker Hillside Hospital, Northwell Health, New York, NY, USA. \\ ${ }^{3}$ Department of Psychiatry, Zucker School of Medicine at Northwell/Hofstra, Hempstead, NY, USA. \\ ${ }^{4}$ University Hospital of Psychiatry and Psychotherapy, University of Bern, Bern, Switzerland. \\ ${ }^{5}$ Department of Psychiatry and Psychotherapy, Technische Universität München, Munich, Germany.
}

\begin{abstract}
An assumption among clinicians and researchers is that patients with schizophrenia vary considerably in their response to antipsychotic drugs in randomized clinical trials (RCTs). To evaluate the overall variation in individual treatment response from random variation by comparing the variability between treatment and control groups. DATA SOURCES Cochrane Schizophrenia, MEDLINE/PubMed, Embase, PsycINFO, Cochrane CENTRAL, BIOSIS Previews, ClinicalTrials.gov, and World Health Organization International Clinical Trials Registry Platform from January 1, 1955, to December 31, 2016. Double-blind, placebo-controlled, RCTs of adults with a diagnosis of schizophrenia spectrum disorders and prescription for licensed antipsychotic drugs. Means and SDs of the Positive and Negative Syndrome Scale pretreatment and posttreatment outcome difference scores were extracted. Data quality and validity were ensured by following the PRISMA guidelines. The outcome measurewas the overall variability ratio of treatment to control in ameta-analysis across RCTs. Individual variability ratios were weighted by the inverse-variance method and entered into a random-effects model. A personal element of response was hypothesized to be reflected by a substantial overall increase in variability in the treatment group compared with the control group. An RCT was simulated, comprising 30 patients with schizophrenia randomized to either the treatment or the control group. The different components of variation in RCTs were illustrated with simulated data. In addition, we assessed the variability ratio in 52 RCTs involving 15360 patients with a schizophrenia or schizoaffective diagnosis. The variability was slightly lower in the treatment compared with the control group (variability ratio $=0.97 ; 95 \% \mathrm{CI}, 0.95-0.99 ; \mathrm{P}=.01$ ). In this study, no evidence was found in RCTs that antipsychotic drugs increased the outcome variance, suggesting no personal element of response to treatment but instead indicating that the variance was slightly lower in the treatment group than in the control group; although the study cannot rule out that subsets of patients respond differently to treatment, it suggests that the average treatment effect is a reasonable assumption for the individual patient.
\end{abstract}

Keywords: individual treatment response, schizophrenia, antipsychotics, positive and negative syndrome scale, personalized medicine, variability ratio.

2 Personalized medicine is based on a widely held assumption

Correspondence concerning this article should be addressed to ${ }^{3}$ Stephanie Winkelbeiner, Ph.D., or Philipp Homan,Feinstein Insti- 4 tute for Medical Research Zucker Hillside Hospital 75-59 263rd 5 Street New York, NY 11004. E-mail: swinkelbei@northwell.edu; 6 phoman1@northwell.edu

\section{Introduction} that patients differ substantially in their response to treatments. The goal of personalized medicine is to find the right treatment for the right patient. Psychiatry is no exception. An assumption among clinicians and researchers alike is that the response to antipsychotic drugs by patients with psychosis differs considerably between individuals (1).

We report that this assumption may be ungrounded. Although variation in the observed treatment responses obvi- 
ously exists, it is crucial to distinguish between observed and 63 true treatment response: observed response consists of true 64 response plus regression to the mean, some placebo effects, 65 and random terms such as (but not restricted to) measurement 66 error. First, we exemplify why confusing observed with true 67 treatment response is so common, and we use simulated data 68 to show how variation that is purely random and unrelated 69 to permanent differences in treatment response may suggest 70 the need for personalized treatment. Next, we review the evi- 71 dence of the differences in treatment response by conducting 72 a meta-analysis of the variation in antipsychotic treatment 73 trials. Although this issue is brought up by statisticians reg- 74 ularly (2), it deserves more attention from a general psychi- 75 atric audience.

Where does the assumption of individual differences in treat- 77 ment response come from? In general, antipsychotic drugs 78 are assessed in randomized clinical trials (RCTs), the crite- 79 rion standard for identifying the efficacy of a treatment. In 80 RCTs, patients are assessed at baseline (eg, with the Posi- 81 tive and Negative Syndrome Scale [PANSS]) and random- 82 ized to either a treatment or a control group. What RCTs ${ }^{83}$ can ultimately provide is an answer to whether a treatment 84 works in general. This average treatment effect is derived 85 from the direct comparison of the response between the treat- 86 ment and the control groups, which is imperative in an RCT 87 (3). Understandably, this answer may leave clinicians unsat- 88 isfied; after all, they are treating individual, and not typical, 89 patients. From a clinical perspective, patients vary consid- 90 erably in their response to antipsychotic drugs, and the gen- 91 eral response may seem almost like an uninformed guess for 92 the individual patient. Furthermore, clinicians seem to pre- 93 fer categories such as normal or abnormal and responders or nonresponders to inform diagnostic and therapeutic deci- 94 sions. A consequence is that many investigators now try to personalize medicine by aiming to tailor treatments to indi- 95 vidual patients. They agree that response to treatment varies from patient to patient.

However, estimating individual response to treatment, known ${ }^{97}$ as the treatment-by-patient interaction, is more complex than ${ }_{98}^{98}$ often appreciated and depends on laborious study designs, ${ }_{100}^{99}$ such as repeated crossover trials (2). However, as we illustrate with simulated data, such study designs are needed to distinguish individual response to treatment from other components of variation that are unrelated to permanent differ- ${ }_{104}{ }^{103}$ ences in treatment response (4-7).

By design, RCTs cannot estimate the treatment-by-patient ${ }^{106}$ interaction, the index of individual response. Although RCTs ${ }^{107}$ do not tell anything about individual response, they might indicate something about the presence of individual response. ${ }_{108}$ As recognized early by Fisher (8), an increase in variance in the treatment group compared with the control group could 109 indicate the presence of variation in response to treatment $t_{110}$
(2). The strength of this increase would then quantify the size of the personal element of response and provide evidence for the presence of a treatment-by-patient interaction (9). A method has been developed to compare variances between groups across studies (10) and has been adopted by a meta-analysis package (11). In psychiatry, this method has been applied to compare variances in brain structure (12) and inflammatory parameters in psychosis (13). This method compares the variance of treatment and control by computing their ratio: a ratio of 1 means equal variances, a ratio greater than 1 means more variability in the treatment group, and a ratio smaller than 1 means less variability in the treatment group compared with the control group $(10,12,13)$.

This study is organized in 2 parts. The first part illustrates the different components of variation in RCTs with simulated data, showing the importance of recognizing the treatmentby-patient interaction (which reflects individual treatment response) as the component of interest. The second part shows the results of a meta-analysis, which tested for the presence of treatment-by-patient interaction in empirical data from antipsychotic drug RCTs. We compared the overall variability in the treatment group with the overall variability in the control group, using data from a recently published metaanalysis (14), summarizing 24 years of placebo-controlled, antipsychotic RCTs in schizophrenia. We hypothesized that compared with control, the often-highlighted heterogeneity in patients with schizophrenia would be reflected by a clinically relevant increase inoverall variance of treatment, outcome, which is compatible with a personal element of response that deviates from the estimated average treatment effects.

\section{Methods}

\section{Trial Simulation}

To illustrate the different components of variation in RCTs,we simulated data from patients with schizophrenia who were randomized to either the antipsychotic treatment or control group and assessed with the PANSS and a positive effect of treatment (Cohen's $d=1.32, t(27.5)=3.46, P=$ 0.002). First, we added a single crossover condition with either a constant or a varying treatment effect, and then we added a double crossover to this simulated trial. With these additions, we show how the variability between and within patients has to be distinguished from the treatment-by- patient interaction, the component reflecting the individual differences in treatment response.

\section{Meta-analysis}

To ensure data quality and validity, this meta-analysis was conducted in accordance with the PRISMA guidelines. 
We searched Cochrane Schizophrenia, MEDLINE/PubMed, 155 Embase, PsycINFO, Cochrane CENTRAL, BIOSIS Pre-156 views, ClinicalTrials.gov, and World Health Organization In-157 ternational Clinical Trials Registry Platform from January 1,158 1955, to December 31, 2016. Using the meta-analysis of 159 Leucht et al. (14) as a basis, we included published and un-160 published double-blind, placebo controlled RCTs of at least ${ }_{61}$ 3 weeks' duration. These studies investigated adults with $a_{162}$ diagnosis of schizophrenia spectrum disorders and prescription for licensed antipsychotic medications, except clozap- ${ }^{-163}$ ine. Studies were excluded if they investigated relapse pre- ${ }^{164}$ vention, patients with predominant negative symptoms, $\mathrm{pa}^{-{ }^{16}}$ tients with major concomitant somatic or psychiatric illness, ${ }^{16}$ or intramuscular formulations of antipsychotic treatment, or ${ }^{167}$ if they were Chinese research. We included only studies that ${ }^{168}$ reported the necessary information (mean, SD, and sample ${ }^{169}$ size) of the PANSS pretreatment and posttreatment outcome difference scores.

In studies that combined comparisons of multiple antipsy- ${ }^{172}$ chotic drugs with placebo, we calculated an aggregated SD173 across all comparisons, leaving only 1 SD per study. We174 extracted the PANSS means and SDs of the pretreatment and 175 posttreatment outcome difference scores as well as the sam-176 ple sizes for the treatment and the control groups. Further in-177 formation on the search strategy is published elsewhere (14).178

\section{Statistical Analysis}

The SDs of the pretreatment and posttreatment outcome difference scores in the treatment and control groups con-181 sist of the same variance components, including the withinpatient variation. The treatment group, however,may also in-182 clude the additional treatment-by-patient interaction, which ${ }^{183}$ could indicate the presence of individual response differ-184 ences. Thus, in the case of a variable treatment effect, an in-185 crease of the variance in the treatment group, compared with ${ }^{186}$ the control group, should be observable. To assess this vari-187 ation, we calculated for each comparison between antipsy-188 chotic and placebo drugs the relative variability of treatment189 and control as the log variability ratio (log VR; (15) with

$$
\log V R=\log \left(\frac{S D_{T x}}{S D_{C t}}\right)+\frac{1}{2\left(n_{T x}-1\right)}-\frac{1}{2\left(n_{C t}-1\right)}
$$

where $S D_{T x}$ was the reported sample SD for treatment, $S D_{C t 195}$ was the reported sample SD for control, $n_{T x}$ was the treat-196 ment sample size, and $n_{C t}$ the control sample size (10). The ${ }_{197}$ corresponding sampling $\left(s_{\log V R}^{2}\right)$ for each comparison be-198 tween antipsychotic and placebo drugs can be expressed as ${ }_{199}$ follows:

$$
s_{\log V R}^{2}=\frac{1}{2\left(n_{T x}-1\right)}+\frac{1}{2\left(n_{C t}-1\right)}
$$

We did not find an association between the pretreatment and posttreatment outcome difference scores and their respective SDs in the data for the control group $(\beta=0.16, P=0.15$; eFigure 1A in the Supplement) or the treatment group ( $\beta=$ $-0.05, P=0.63$; eFigure 1B in the Supplement). For this reason, we did not consider the log coefficient of variation ratio ( $\log$ CVR) as an additional index for comparing variabilities (10).

We weighted each log VR with the inverse of this sampling variance (11) and entered it into a random-effects model. This approach allows for the quantification of the true individual response, after adjusting for within-patient variability and regression to the mean $(5,9)$. Results were backtransformed from the log scale for better interpretability, with a variability ratio higher than 1 , indicating greater variability under treatment compared with control, and a ratio lower than 1 indicating less variability under treatment compared with control.

The analysis was performed from October 31, 2018, to March 29, 2019, with the R package metafor, version 2.0.0 (11)), and the manuscript was produced with the R package knitr, version 1.20, in RStudio (R Foundation for Statistical Computing). All the data and code we used are freely available online to ensure reproducibility (https://doi.org/10. 17605/OSF.IO/QARVS).

\section{Results}

\section{Simulation}

We simulated an RCT of 30 patients with schizophrenia randomized to either the treatment or the control group. The individual pretreatment and posttreatment outcome differences (Fig. 1A) might tempt us to infer that some patients in the treatment group responded better than others. We might then rank these patients according to their outcome and classify them as either responders or nonresponders. However, such ranking and classification can be misleading.

Although seemingly different (Fig. 2A), adding a simulated crossover condition to the initial parallel trial may reveal that the apparent differences in improvement among patients in the treatment group vanish (Fig. 2B) and the treatment effect may actually be constant across patients (Fig. 2C). Such a scenario cannot be ruled out from the results of a parallel group trial. In addition, the same ranking (Fig. 2A) may reflect yet another scenario, in which differences in improvement as calculated from a crossover condition may reverse the ranking (Fig. 2D), such that patients who appeared to have improved the most had actually the smallest net improvement (Fig. 2E). Apparent outcome differences among patients in an RCT may still be compatible with a constant treatment effect. 


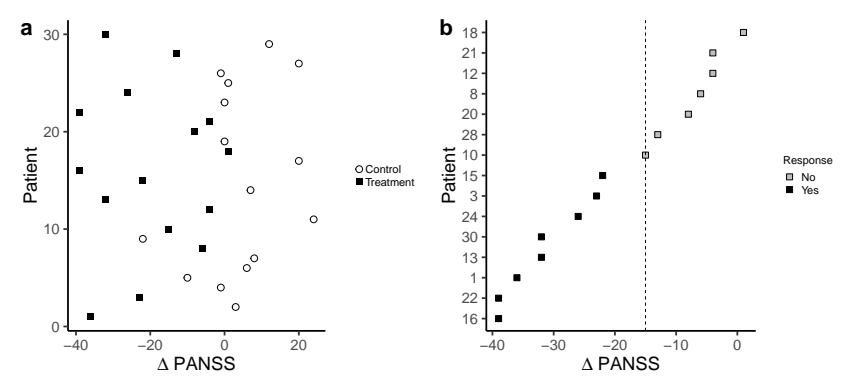

Figure 1. A, Thirty patients with schizophrenia were randomized to either the antipsychotic treatment or the control group. Despite the trial being simulated, with a main effect of treatment $($ Cohen $\mathrm{d}=1.32 ; \mathrm{t}(27.5)=3.46 ; \mathrm{P}=.002)$, it may be tempting to infer from the Positive and Negative Syndrome Scale (PANSS) pretreatment and posttreatment outcome difference scores that some patients in the treatment group responded better than others. This observed pretreatment and posttreatment outcome difference can be misleading given that individual differences might be merely some unexplained components of variance. B, The treatment group patients are ranked according to the observed pretreatment and posttreatment outcome differences and classified as responders or nonresponders based on an arbitrary threshold (dashed light blue line). Although the ranking is not necessary for the classification, it increases the perception of individual differences in response to treatment.

Next, outcome differences may also be found within patients. Assessing patients repeatedly over time might reveal that symptoms fluctuate randomly around the same mean score (Fig. 3). This fluctuation shows that within-patient variability alone may suggest differences in treatment response that are a mere reflection of random fluctuation.

Again, we can add a simple crossover condition to the simulated parallel group trial (Fig. 4A), in which each patient received both the treatment (antipsychotic drug) and control (placebo). Only by running the crossover trial once again (Fig. 4B) can we determine whether the differences observed in the first crossover trial are indeed stable features of the patients. The net improvement from crossover trial 1 may not replicate in crossover trial 2, which indicates that the response differences are still not stable features of the patients (Fig. 4C). For that stability to be the case, we would have to see a similar outcome in crossover trial 1 (Fig. 4A) as in crossover trial 2 (Fig. 4D), in which case we have identified a substantial treatment-by-patient interaction (Fig. 4E).

A careful distinction of the sources of variation in a simulated RCT has shown that it is not trivial to distinguish the source of primary interest (treatment-by-patient interaction) from components that tell nothing about individual response. In the meta-analysis, we assessed whether evidence
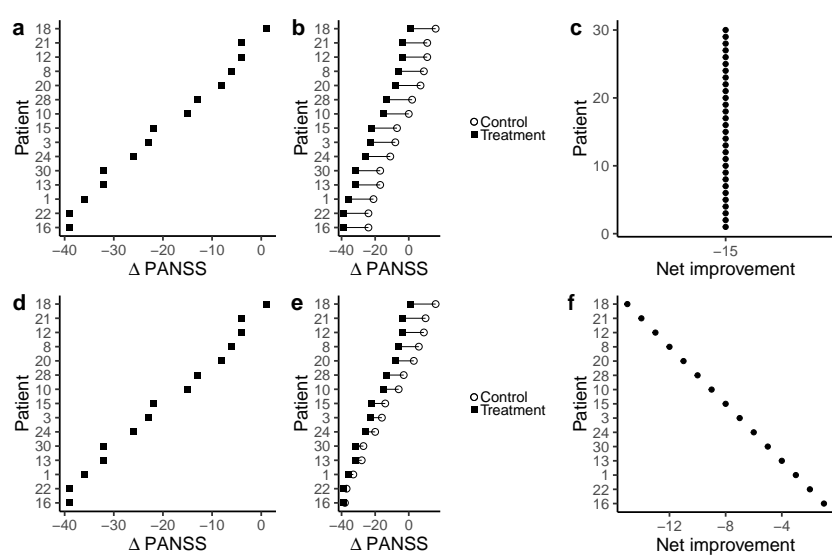

Figure 2. Two simulated scenarios are shown: one with a constant treatment effect across patients (A-C), and one with a reversed ranking after a control condition is taken into account (D, E). A, Using the same ranking from the simulated parallel trial, we show that ranking is a flawed approach to quantifying symptom improvement. $\mathrm{B}$, When adding a control condition to the initial parallel trial, the seeming differences in improvement from patients in the treatment group vanish. $\mathrm{C}$, The crossover trial simulation eliminates spurious differences in the outcome and reveals no between-patient differences in response. Although seemingly unlikely, such a scenario cannot be ruled out from the results of a parallel group trial. In another scenario, a variable treatment effect is added to a parallel trial (A). D, Differences in improvement may reverse the ranking if patients varied in their response to the treatment compared with controls. E, The patient who appeared to have improved the most in D had actually the smallest net improvement. PANSS indicates Positive and Negative Syndrome Scale.
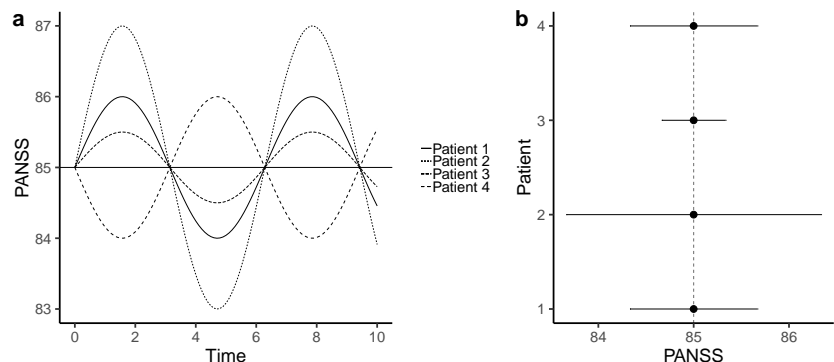

Figure 3. Four patients from the simulated trial were measured repeatedly over time using the Positive and Negative Syndrome Scale (PANSS). A, The differences in a patient's symptom severity scores from time point to time point are independent of any intervention. B, Measuring repeatedly and calculating the means over all time points account for random within-patient fluctuations and reveal that patients had the same mean PANSS score. What differed was the amount of random fluctuation, which might be a highly unlikely scenario but, until tested, cannot be assumed is not true. 

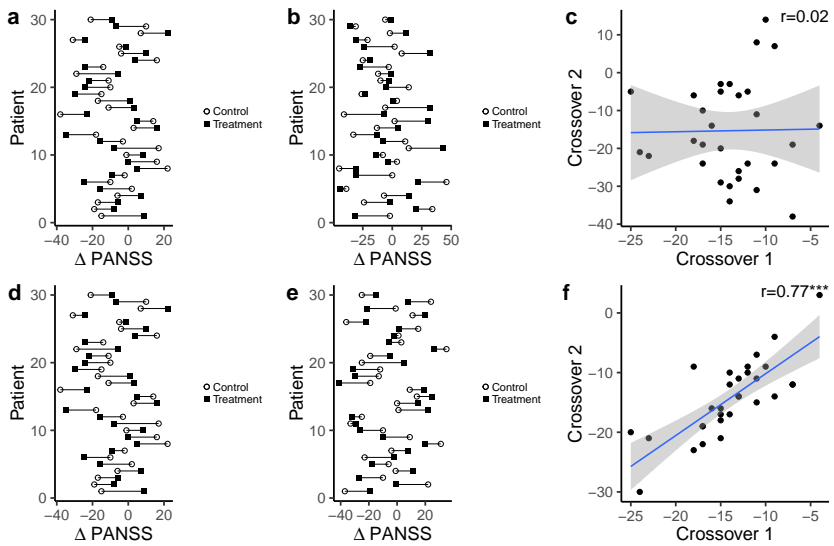

Figure 4. The same simulation is shown of 30 patients with schizophrenia in a parallel trial assessed with the Positive and Negative Syndrome Scale (PANSS). A, Patients received both the antipsychotic and placebo drugs in a crossover trial. $\mathrm{B}$, Only by running a crossover trial more than once can we identify whether individual response is a trait or a permanent feature of the patient. C, Associating the net improvement from crossover trials 1 and 2 (solid dots) shows that advantages from the first trial do not replicate in the second $(\mathrm{r}=$ $0.02 ; 95 \% \mathrm{CI}$ ). In this scenario, response to treatment is not a permanent feature of the patient. D, Another scenario using the same crossover trial 1 (A) and repeating it, we might observe that the response was almost identical to the response in crossover trial 1. E, Patients responded similarly in both ${ }^{243}$ trials $(r=0.77 ; 95 \% \mathrm{CI})$. In this scenario, we can consider ${ }^{244}$ response to treatment as a trait in these patients. Repeata- ${ }^{245}$ bility of the association from one crossover trial to the next $\mathrm{t}^{246}$ in the same sample is the only way to separate treatment-by- $-{ }^{247}$ patient interaction from random within-patient variation and ${ }^{248}$ to determine whether response is a trait or a state.

exists for such treatment-by-patient interaction across an-252 tipsychotic drug trials.

\section{Meta-analysis}

We investigated 75 comparisons of antipsychotic drug with ${ }^{254}$ placebo in 52 RCTs (16-67). None of these studies used a ${ }^{255}$ design such as repeated crossovers thatwould have allowed ${ }^{256}$ for a direct estimate of individual responses. Overall, a to- ${ }^{257}$ tal of 15360 patients with a schizophrenia or schizoaffective ${ }^{258}$ diagnosis were included, of whom $8550(56 \%)$ had been ran- ${ }^{259}$ domized to the treatment group and 6810 (44\%) to the con- ${ }^{260}$ trol group (more details can be found in the eResults in the $\mathrm{e}^{261}$ Supplement).

We found an overall lower variability in treatment compared 264 with control ( $V R=0.97,95 \%$ CI: 0.95, 0.99, $P=0.01$; (Fig.265 5 ; (16-67). This finding indicates that the overall variability266
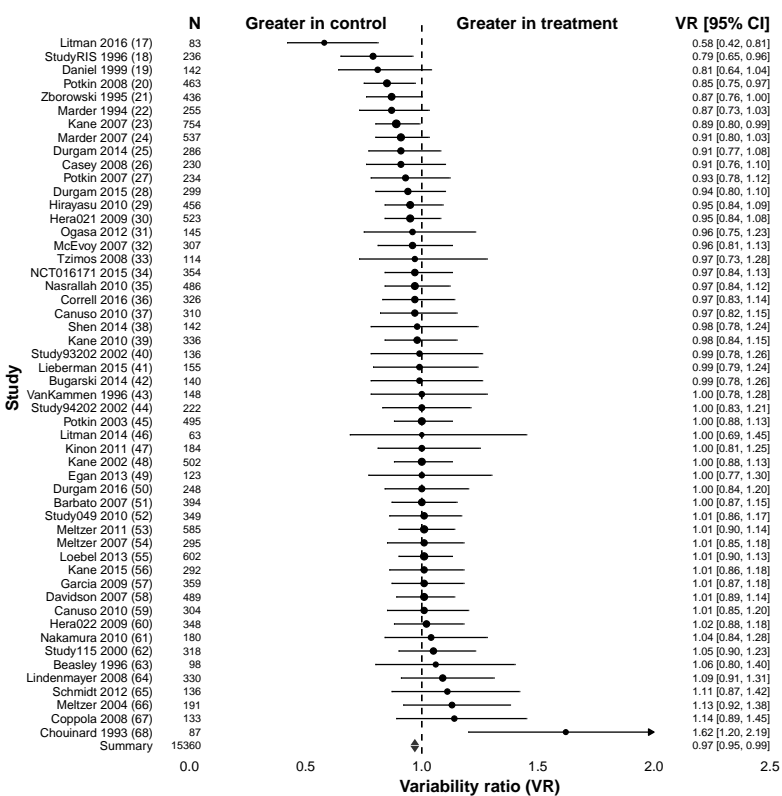

Figure 5. The forest plot shows the VR together with its $95 \%$ CI for treatment vs control across 52 studies. Each study is listed with its respective citation number. The overall VR was lower for treatment compared with control group.

across treatment groups was 3\% lower compared with that in the control groups. Furthermore, we compared the variances in individual antipsychotic drug outcome and found the same pattern, with lower variability across treatment compared with control $(V R=0.97,95 \% \mathrm{CI}$ : $0.95,1, P=0.02$; eFigure 2 in the Supplement).

No evidence was found that antipsychotic treatment increased the outcome variance compared with the control. Instead, the outcome variance was slightly lower in the treatment than in the control group.

\section{Discussion}

A widespread belief among clinicians and researchers is that patients differ substantially in their antipsychotic treatment response, but finding evidence for this assumption is complex. A likely explanation, supported by the simulations conducted for this study, is that taking an observed treatment response as the true treatment response is tempting, compelling us to ignore the components of variation most likely encountered: random variation within patients and differences between patients. The existing empirical evidence for such individual differences is weaker than expected: No evidence was found that the antipsychotic drug increased the outcome variance compared with the placebo. Instead, the outcome variance was slightly lower in the treatment group.With this 
finding, we still cannot rule out that subsets of patients re-319 sponded differently to treatment, but the overall small differ- -320 ence in variances suggests that the average treatment effect 321 is a reasonable assumption for the individual patient. By as-з22 suming heterogeneity in treatment outcomes, we might ulti-з2з mately introduce noise into clinical practice by refusing to go with the best available evidence, the average treatment effect ${ }^{324}$ derived from RCTs (2).

Although RCTs are questioned regularly, sometimes using questionable arguments (68), they remain the criterion stan- ${ }_{328}$ dard in clinical research. They provide unbiased estimates of $\mathrm{f}_{329}$ the relative efficacy of an intervention, which even the largest ${ }_{330}$ observational studies cannot provide (69). In addition, appre- ${ }_{331}$ ciating the role of randomization in RCTs is important. Ran- ${ }_{332}$ domization is not compatible with the notion that specific $_{333}$ features, such as placebo response, increase in one but not $_{334}$ the other group in anRCT. If evidence existed of an enhanced ${ }_{335}$ placebo response over time, as has been suggested repeatedly $y_{336}$ in the past years (14), this response would have been apparent in both the control and the treatment groups because of randomization and thus would have canceled out. Furthermore, ${ }_{337}$ the concept of placebo response, although regularly investigated (70), cannot be studied by looking at the observed responses in control groups (71), for the same reasons that ${ }^{338}$ this approach does not work for the treatment groups, as this ${ }^{339}$ study has shown.

Comparing the variabilities between treatment and control $_{342}$ groups may provide valuable insight into the presence of in- -343 dividual response and the scope of personalized medicine.344 Recently, other groups have taken a similar approach to as-345 sess the presence of individual differences in brain struc-346 ture (12) and immunological parameters in psychosis (13). . $_{44}$ We assumed that, in the presence of a personal elementof ${ }_{348}$ response to treatment, the variance in the treatment group 349 should be higher compared with the control group, which in ${ }_{350}$ turn would require further investigation (eg, with n-of-1 tri-351 als (72-74)). However, our results indicate that overall vari-352 ability in the treatment groups was slightly lower, if only by a modest amount (1\% to $5 \%$ ). One explanation might be $\mathrm{b}_{354}$ that the treatment had a stabilizing quality (9) that reduced ${ }_{355}$ the variability in the treatment group. An example for $\operatorname{such}_{356}$ variance stabilization might be the floor effect, in which the ${ }_{357}$ assessment instrument is too coarse to capture patient im-358 provements over a certain level.

Nevertheless, given the slightly lower variability under treatment compared with control found in this study,we cannot ${ }^{359}$ rule out that individual differences in response to antipsychotic drugs might still exist. A subset of ill patients mays60 have responded well to treatment, whereas less affected pa-361 tients may not have improved, resulting in an overall de-362 creased variance under treatment than under control (9). Yet,363 the finding of a narrow CI around an overall only slightly ${ }_{364}$ lower variability suggests that substantial differences in drug response are rather unlikely. Thus, analyses aimed at estimating individual response might be premature until these differences have been shown to exist and to be clinically relevant.

As the simulations have shown, labeling patients as responders might be misleading. The label suggests that true response has been established as a permanent feature of the patient, even though the label is a mere reflection of the observed response, which includes true response plus regression to the mean, some placebo effect, and random terms such as measurement error. Thus, response rates that are calculated in RCTs reflect observed but not true response. We suggest that biomarker research aimed at identifying response to treatment of individuals or subgroups should consider the possibility that treatment outcome is less heterogeneous than anticipated and might even be close to constant across individuals.

\section{Limitations}

This meta-analysis has some limitations. First, the calculation of the pretreatment and posttreatment outcome difference scores varied between studies. Although some RCTs calculated the differences between outcome and baseline PANSS scores, others used analysis of covariances with the baseline PANSS scores and additional variables as covariates. Thus, some of the included SDs of change were adjusted for covariates but otherswere not. Second, the use of pretreatment and posttreatment outcome difference scores might lead to a loss of information and might not be sensitive enough to capture differences in response to treatment (75). Third, we assumed that individual responses to treatment were reflected by increased variance in the treatment group. Yet, this increased variance could have also indicated the presence of subgroups who responded differently to the treatment (9). Such a case would argue for stratified medicine rather than personalized medicine, in which subgroups of patients receive varying treatments. As any interaction, a treatment-by-patient interaction is ultimately scale dependent, which means it can be removed by transformation of the scale (76).

\section{Conclusions}

Until the differences in individual response to treatment have been demonstrated with careful designs, the overall small differences in outcome variance suggest that the average treatment effect is a reasonable assumption for the individual patient. 
Additional Contributions

The authors thank Majnu John, PhD, Department of Mathe- ${ }_{411}$ matics, Zucker School of Medicine at Northwell/Hofstra, for ${ }_{412}$ advice on the analysis of the current study, as well as Stephen ${ }_{413}$ Senn, PhD, Methodology and Statistics, Luxembourg Institute of Health, and Daniel Guinart, MD, Department of Psy-414 chiatry, Zucker School of Medicine at Northwell/Hofstra, ${ }^{415}$ for helpful comments on the manuscript. These individuals ${ }_{416}$ received no additional compensation, outside of their usual ${ }_{417}$ salary, for their contributions.

\section{Author Contributions}

Author Contributions: Drs Homan and Winkelbeiner had full access to all of the data in the study and take respon- ${ }_{423}$ sibility for the integrity of the data and the accuracy of the ${ }_{424}$ data analysis. Concept and design: Winkelbeiner, Leucht, ${ }_{125}$ Homan. Acquisition, analysis, or interpretation of data: *All authors. Drafting of the manuscript:* Winkelbeiner, Homan. ${ }^{426}$ Critical revision of the manuscript for important intellectual ${ }^{27}$ content:* All authors. Statistical analysis:* Winkelbeiner, ${ }^{428}$ Homan. Obtained funding: Winkelbeiner. Administrative, ${ }^{429}$ technical, or material support: All authors. Supervision: 430 Homan.

\section{Conflict of Interest Disclosures}

Dr Winkelbeiner reported grants from Swiss National Sci- ${ }^{435}$ ence Foundation during the conduct of the study. Dr Leucht436 reported personal fees from LB Pharma International, $\mathrm{H}_{437}$ Lundbeck A/S, Otsuka Pharmaceutical, Teva Pharmaceuti-438 cal Industries Ltd, LTS Lohmann Therapy Systems, Gedeon439 Richter, Recordati SpA, MSD, Boehringer Ingelheim and 440 Sandoz, Janssen Pharmaceutica, Eli Lilly \& Company,441 SanofiAventis, and Servier Laboratorie outside of the submit-442 ted work; reanalysis of a clinical trial together with Geodon Richter and the publication of its results; and honoraria from ${ }^{443}$ Johnson \& Johnson, MSD, Angelini, and Sunovion. Dr Kane reported grants from Otsuka, Lundbeck, and Janssen, as well ${ }^{445}$ as other from Alkermes, Allergan, Forum, Genentech, Lund- ${ }_{447}^{446}$ beck, Intracellular Therapies, Janssen, Johnson \& Johnson, Merck, Neurocrine, Otsuka, Pierre Fabre, Reviva, Roche,448 Sunovion, Takeda, Teva, Vanguard Research Group, and LB 449 Pharmaceuticals outside of the submitted work. No other450 disclosures were reported.

\section{References}

1. Garver DL, Holcomb JA, Christensen JD. Heterogeneity 455 of response to antipsychotics from multiple disor-456 ders in the schizophrenia spectrum. The Journal of Clinical Psychiatry. 2000;61(12):964-72.

2. Senn S. Mastering variation: variance components and personalised medicine. Statistics in Medicine. 2016;35(7):966-77.

3. Senn S. Trying to be precise about vagueness. Statistics in Medicine. 2007;26(7):1417-30.

4. Homan P, Kane J. Clozapine as an early-stage treatment. Acta Psychiatrica Scandinavica. 2018;138:279-80.

5. Hecksteden A, Kraushaar J, Scharhag-Rosenberger F, Theisen D, Senn S, Meyer T. Individual response to exercise training-a statistical perspective. Journal of Applied Physiology. 2015;118(12):1450-9.

6. Hecksteden A, Pitsch W, Rosenberger F, Meyer T. Repeated testing for the assessment of individual response to exercise training. Journal of Applied Physiology. 2018;124(6):1567-79.

7. Dworkin RH, McDermott MP, Farrar JT, O'connor AB, Senn S. Interpreting patient treatment response in analgesic clinical trials: implications for genotyping, phenotyping, and personalized pain treatment. Pain. 2014;155(3):457-60.

8. Bennett e JH. Statistical Inference and Analysis: Selected Correspondence of RA Fisher. Oxford, UK: Claredon Press; 1990; Cited by: Senn S. Sevenmyths of randomisation in clinical trials. Stat Med. 2013;32(9): 1439-1450. doi:10.1002/sim.5713.

9. Cortés J, González JA, Medina MN, Vogler M, Vilaró M, Elmore M, et al. Does evidence support the high expectations placed in precision medicine? A bibliographic review [version 4; peer review: 1 approved with reservations, 3 not approved]. F1000Research [En ligne]. 2019;7(30). Disponible: https://doi.org/ 10.12688/f1000research.13490.4

10. Nakagawa S, Poulin R, Mengersen K, Reinhold K, Engqvist L, Lagisz M, et al. Meta-analysis of variation: ecological and evolutionary applications and beyond. Methods in Ecology and Evolution. 2015;6(2):143-52.

11. Viechtbauer W. Conducting meta-analyses in $\mathrm{R}$ with the metafor package. Journal of Statistical Software [En ligne]. 2010;36(3):1-48. Disponible: http://www.jstatsoft.org/v36/i03/

12. Brugger SP, Howes OD. Heterogeneity and homogeneity of regional brain structure in schizophrenia: a metaanalysis. JAMA Psychiatry. 2017;74(11):1104-11.

13. Pillinger T, Osimo EF, Brugger S, Mondelli V, McCutcheon RA, Howes OD. A Meta-analysis of Im- 
mune Parameters, Variability, and Assessment of $f_{506}$ Modal Distribution in Psychosis and Test of the Im-507 mune Subgroup Hypothesis. Schizophrenia Bulletin. [published November 8, 2018];

14. Leucht S, Leucht C, Huhn M, Chaimani A, Mavridis D, ${ }_{510}$ Helfer B, et al. Sixty years of placebo-controlled ${ }_{511}$ antipsychotic drug trials in acute schizophrenia: ${ }_{512}$ systematic review, Bayesian meta-analysis, and meta-regression of efficacy predictors. American $^{513}$ Journal of Psychiatry. 2017;174(10):927-42. $\quad 514$

15. Hedges LV, Nowell A. Sex differences in mental test ${ }_{516}^{515}$ scores, variability, and numbers of high-scoring in- ${ }_{517}$ dividuals. Science. 1995;269(5220):41-5.

16. Litman RE, Smith MA, Doherty JJ, Cross A, Raines S, Gertsik L, et al. AZD8529, a positive allosteric ${ }_{520}$ modulator at the mGluR2 receptor, does not im- ${ }_{52}$ prove symptoms in schizophrenia: A proof of prin- $^{-}{ }_{522}$ ciple study. Schizophrenia Research. 2016;172(1- ${ }_{523}$ 3):152-7.

17. StudyRIS. Office of Clinical pharmacology and biopharmacy review. NDA number: 20272. ${ }^{525}$ Janssen-Cilag; data on file. Cited by: Leuch ${ }_{527}^{526}$ S, Leucht C, Huhn M, et al. Sixty years ${ }^{527}$ of placebo-controlled antipsychotic drug trials in ${ }^{528}$ acute schizophrenia: systematic review, bayesian ${ }_{529}$ meta-analysis,; meta-regression of efficacy predic-530 tors. Am J Psychiatry. 2017;174(10):927-942.531 doi:10.1176/appi.ajp.2017.16121358; 1996;

18. Daniel DG, Zimbroff DL, Potkin SG, Reeves $\mathrm{KR}^{533}$ Harrigan EP, Lakshminarayanan M. Ziprasidone ${ }_{534}$ $80 \mathrm{mg} /$ day and $160 \mathrm{mg} /$ day in the acute exac- ${ }_{535}$ erbation of schizophrenia and schizoaffective dis- ${ }_{536}$ order: a 6-week placebo-controlled trial. $\mathrm{Neu}_{537}$ ropsychopharmacology. Nature Publishing Group; ${ }_{538}$ 1999;20(5):491.

19. Potkin SG, Litman RE, Torres R, Wolfgang CD. Effi ${ }^{539}$ cacy of iloperidone in the treatment of schizophre- ${ }_{541}$ nia: initial phase 3 studies. Journal of Clinical Psy- ${ }_{542}$ chopharmacology. 2008;28(2):4-11.

20. Zborowski J, Schmitz P, Staser J, O’Neil J, Giles K, ${ }^{544}$ Wallin B, et al. Efficacy and safety of sertindole in a trial of schizophrenic patients. Biological Psy ${ }_{546}^{545}$ chiatry. 1995;9(37):661-2.

21. Marder SR, Meibach RC. Risperidone in the treatment of 548 schizophrenia. The American Journal of Psychiatry. 1994;151(6):825.

22. Kane J, Canas F, Kramer M, Ford L, Gassmann-551 Mayer C, Lim P, et al. Treatment of schizophre-552 nia with paliperidone extended-release tablets: a 6-553 week placebo-controlled trial. Schizophrenia Research. 2007;90(1-3):147-61.

23. Marder SR, Kramer M, Ford L, Eerdekens E, Lim P, Eerdekens M, et al. Efficacy and safety of paliperidone extended-release tablets: results of a 6-week, randomized, placebo-controlled study. Biological Psychiatry. 2007;62(12):1363-70.

24. Durgam S, Starace A, Li D, Migliore R, Ruth A, Németh $G$, et al. An evaluation of the safety and efficacy of cariprazine in patients with acute exacerbation of schizophrenia: a phase II, randomized clinical trial. Schizophrenia Research. Elsevier; 2014;152(2-3):450-7.

25. Casey DE, Sands EE, Heisterberg J, Yang H-M. Efficacy and safety of bifeprunox in patients with an acute exacerbation of schizophrenia: results from a randomized, double-blind, placebo-controlled, multicenter, dose-finding study. Psychopharmacology. 2008;200(3):317-31.

26. Potkin SG, Cohen M, Panagides J. Efficacy and tolerability of asenapine in acute schizophrenia: a placeboand risperidone-controlled trial. The Journal of Clinical Psychiatry. 2007;68(10):1492-500.

27. Durgam S, Cutler A, Lu K et a. Cariprazine in acute exacerbation of schizophrenia: a fixed-dose, phase 3 , randomized, double-blind, placebo-and activecontrolled trial. The Journal of Clinical Psychiatry. 2015;76(12):e1574-82.

28. Hirayasu Y, Tomioka M, Iizumi M, Kikuchi H. A doubleblind, placebo-controlled, comparative study of paliperidone extended release (ER) tablets in patients with schizophrenia. Jpn J Clin Psychopharmacol. 2010;13:2077-103.

29. A multicenter, randomized, double-blind, fixed-dose, 6week trial of the efficacy and safety of asenapine compared with placebo using olanzapine positive control in subjects with an acute exacerbation of schizophrenia. Center for drug evaluation; research Medical review(s). 2009;

30. Ogasa M, Kimura T, Nakamura M, Guarino J. Lurasidone in the treatment of schizophrenia: a 6-week, placebo-controlled study. Psychopharmacology. 2013;225(3):519-30.

31. McEvoy JP, Daniel DG, Carson Jr WH, McQuade RD, Marcus RN. A randomized, double-blind, placebo-controlled, study of the efficacy and safety of aripiprazole 10,15 or $20 \mathrm{mg} /$ day for the treatment of patients with acute exacerbations of 
schizophrenia. Journal of Psychiatric Research.603 2007;41(11):895-905.

32. Tzimos A, Samokhvalov V, Kramer M, Ford L, ${ }^{605}$ Gassmann-Mayer C, Lim P, et al. Safety and ${ }^{606}$ tolerability of oral paliperidone extended-release ${ }^{607}$ tablets in elderly patients with schizophrenia: $a^{608}$ double-blind, placebo-controlled study with six- ${ }_{609}$ month open-label extension. The American Journal ${ }_{610}$ of Geriatric Psychiatry. 2008;16(1):31-43.

611

33. ClinicalTrials.gov. A study of the efficacy and safety ${ }^{612}$ of asenapine in participants with an acute exac- ${ }^{613}$ erbation of schizophrenia (P05688). Identifier: ${ }^{614}$ NCT01617187; Accessed October 31, 2016; $\quad 615$

34. Nasrallah HA, Silva R, Phillips D, Cucchiaro J, Hsu J, ${ }^{616}$ $\mathrm{Xu} \mathrm{J}$, et al. Lurasidone for the treatment of acutely ${ }^{617}$ psychotic patients with schizophrenia: a 6-week, ${ }^{618}$ randomized, placebo-controlled study. Journal of 619 Psychiatric Research. 2013;47(5):670-7. $\quad 620$

35. Correll CU, Skuban A, Hobart M, Ouyang J, Weiller ${ }_{622}^{621}$ $\mathrm{E}$, Weiss C, et al. Efficacy of brexpiprazole in pa- ${ }_{623}$ tients with acute schizophrenia: review of three ran- ${ }_{624}$ domized, double-blind, placebo-controlled studies ${ }_{625}$ Schizophrenia Research. 2016;174(1-3):82-92.

36. Canuso CM, Schooler N, Carothers J, Turkoz $\mathrm{I}_{\text {,627 }}$ Kosik-Gonzalez C, Bossie CA, et al. Paliperi-628 done extended-release in schizoaffective disorder: 629 a randomized, controlled study comparing a flex-630 ible dose with placebo in patients treated with $_{631}$ and without antidepressants and/or mood stabi- ${ }_{632}$ lizers. Journal of Clinical Psychopharmacology. 2010;30(5):487-95.

37. Shen JH, Zhao Y, Rosenzweig-Lipson S, Popp D,635 Williams JB, Giller E, et al. A 6-week randomized,636 double-blind, placebo-controlled, comparator refer-637 enced trial of vabicaserin in acute schizophrenia.638 Journal of Psychiatric Research. 2014;53:14-22.

38. Kane JM, Cohen M, Zhao J, Alphs L, Panagides J. ${ }^{640}$ Efficacy and safety of asenapine in a placebo-and ${ }^{641}$ haloperidol-controlled trial in patients with acute ${ }^{642}$ exacerbation of schizophrenia. Journal of Clinical ${ }^{643}$ Psychopharmacology. 2010;30(2):106-15. $\quad{ }_{644}$

39. Study93202. Center for Drug Evaluation and Research. Application number 21-436. Medical review (s). ${ }^{646}$ Cited by: Leucht S, Leucht C, Huhn M, et al. Sixty ${ }^{647}$ years of placebo-controlled antipsychotic drug tri- ${ }^{648}$ als in acute schizophrenia: systematic review, ${ }^{649}$ bayesianmeta-analysis, andmeta-regression of ef- ${ }^{650}$ ficacy predictors.AmJ Psychiatry. 2017;174(10): ${ }^{651}$ 927-942. doi:10.1176/appi.ajp.2017.16121358;652
2002;

40. Lieberman JA, Davis RE, Correll CU, Goff DC, Kane JM, Tamminga CA, et al. ITI-007 for the treatment of schizophrenia: A 4-week randomized, double-blind, controlled trial. Biological Psychiatry. 2016;79(12):952-61.

41. Bugarski-Kirola D, Wang A, Abi-Saab D, Blättler T. A phase II/III trial of bitopertin monotherapy compared with placebo in patients with an acute exacerbation of schizophrenia-results from the CandleLyte study. European Neuropsychopharmacology. 2014;24(7):1024-36.

42. Van Kammen DP, McEvoy JP, Targum SD, Kardatzke D, Sebree TB. A randomized, controlled, dose-ranging trial of sertindole in patients with schizophrenia. Psychopharmacology. 1996;124(1-2):168-75.

43. Study94202. Center for drug evaluation and research. Application number 21-436. Medical review(s). Cited by: Leucht S, Leucht C, Huhn M, et al. Sixty years of placebo-controlled antipsychotic drug trials in acute schizophrenia: systematic review, bayesian meta-analysis,; meta-regression of efficacy predictors. Am J Psychiatry. 2017;174(10):927-942. doi:10.1176/appi. ajp.2017.16121358; 2002;

44. Potkin SG, Saha AR, Kujawa MJ, Carson WH, Ali M, Stock E, et al. Aripiprazole, an antipsychotic with a novel mechanism of action, and risperidone vs placebo in patients with schizophrenia and schizoaffective disorder. Archives of General Psychiatry. 2003;60(7):681-90.

45. Litman RE, Smith MA, Desai DG, Simpson T, Sweitzer $\mathrm{D}$, Kanes SJ. The selective neurokinin 3 antagonist AZD2624 does not improve symptoms or cognition in schizophrenia: a proof-of-principle study. Journal of Clinical Psychopharmacology. 2014;34(2):199-204.

46. Kinon BJ, Zhang L, Millen BA, Osuntokun OO, Williams JE, Kollack-Walker S, et al. A multicenter, inpatient, phase 2, double-blind, placebocontrolled dose-ranging study of LY2140023 monohydrate in patients with DSM-IV schizophrenia. Journal of Clinical Psychopharmacology. 2011;31(3):349-55.

47. Kane JM, Carson WH, Saha AR, McQuade RD, Ingenito GG, Zimbroff DL, et al. Efficacy and safety of aripiprazole and haloperidol versus placebo in patients with schizophrenia and schizoaffective disorder. The Journal of Clinical Psychiatry. 2002;63(9):763-71.

48. Egan MF, Zhao X, Smith A, Troyer MD, Uebele VN, 
Pidkorytov V, et al. Randomized controlled study 703 of the T-type calcium channel antagonist MK-8998704 for the treatment of acute psychosis in patients with 705 schizophrenia. Human Psychopharmacology: Clinical and Experimental. 2013;28(2):124-33.

49. Durgam S, Litman RE, Papadakis $\mathrm{K}, \mathrm{Li}$, 708 Németh G, Laszlovszky I. Cariprazine in the 709 treatment of schizophrenia: a proof-of-concept $t_{710}$ trial. International Clinical Psychopharmacology.711 2016;31(2):61.

50. Barbato L, Newcomer J, Heisterberg J, Yeung P, Shapira ${ }_{713}$ N. Efficacy and metabolic profile of bifeprunox $\mathrm{in}_{714}$ patients with schizophrenia. Paper presented at: $:_{715}$ 11th International Congress on Schizophrenia $\mathrm{Re}_{-716}$ search, Colorado Springs, CO; 2007;

717

51. Study049. A 6-week, double-blind, randomized, fixed ${ }^{718}$ dose, parallel-group study of the efficacy and safety ${ }_{719}$ of three dose levels of SM-13496 (lurasidone) com- $^{-720}$ pared to placebo and haloperidol in patients with $_{721}$ schizophrenia who are experiencing an acute $\mathrm{ex}^{-}{ }_{722}$ acerbation of symptoms. Center for Drug Evalu- ${ }_{723}$ ation and Research; Medical review(s). Cited by: $:_{724}$ Leucht S, Leucht C, Huhn M, et al. Sixty years ${ }_{725}$ of placebo-controlled antipsychotic drug trials $\mathrm{in}_{726}$ acute schizophrenia: systematic review, bayesian ${ }_{727}$ meta-analysis, andmeta-regression of efficacy pre- ${ }_{728}$ dictors.AmJ Psychiatry. 2017;174(10):927-942. ${ }_{729}$ doi:10.1176/appi.ajp.2017.16121358; 2010;

52. Meltzer HY, Cucchiaro J, Silva R, Ogasa M, Phillips ${ }_{731}$ $\mathrm{D}, \mathrm{Xu} \mathrm{J}$, et al. Lurasidone in the treatment ${ }_{732}$ of schizophrenia: a randomized, double-blind, ${ }_{733}$ placebo-and olanzapine-controlled study. Ameri- ${ }_{734}$ can Journal of Psychiatry. 2011;168(9):957-67.

53. Meltzer H, Barbato L, Heisterberg J, Yeung P, Shapira N. A randomized, double-blind, placebo-controlled ${ }_{737}{ }^{36}$ efficacy and safety study of bifeprunox as treatment ${ }_{738}$ for patients with acutely exacerbated schizophrenia. ${ }_{739}$ Schizophrenia Bulletin; 2007;33(2):446-6.

740

54. Loebel A, Cucchiaro J, Sarma K, Xu L, Hsu C,741 Kalali AH, et al. Efficacy and safety of lurasi-742 done $80 \mathrm{mg} /$ day and $160 \mathrm{mg} / \mathrm{day}$ in the treat-743 ment of schizophrenia: a randomized, double-blind, ${ }^{744}$ placebo-and active-controlled trial. Schizophrenia ${ }_{745}$ Research. 2013;145(1-3):101-9.

55. Kane JM, Zukin S, Wang Y, Lu K, Ruth A, Nagy K, et747 al. Efficacy and safety of cariprazine in acute ex-748 acerbation of schizophrenia: results from an international, phase III clinical trial. Journal of Clinical ${ }_{750}^{749}$ Psychopharmacology. 2015;35(4):367-73.

751

56. Garcia E, Robert M, Peris F, Nakamura H, Sato752
N, Terazawa Y. The efficacy and safety of blonanserin compared with haloperidol in acute-phase schizophrenia. CNS Drugs. 2009;23(7):615-25.

57. Davidson M, Emsley R, Kramer M, Ford L, Pan G, Lim P, et al. Efficacy, safety and early response of paliperidone extended-release tablets (paliperidone ER): results of a 6-week, randomized, placebo-controlled study. Schizophrenia Research. 2007;93(1-3):117-30.

58. Canuso CM, Lindenmayer J-P, Kosik-Gonzalez C, Turkoz I, Carothers J, Bossie CA, et al. A randomized, double-blind, placebo-controlled study of 2 dose ranges of paliperidone extended-release in the treatment of subjects with schizoaffective disorder. The Journal of Clinical Psychiatry. 2010;71(5):587-98.

59. 'Hera022, SH SH0-0. A multicenter, randomized, double-blind, fixed-dose, 6-week trial of the efficacy and safety of asenapine compared with placebo using olanzapine postive control in subjects with an acute exacerbation of schizophrenia. Center for drug evaluation; research; Medical review(s). Cited by: Leucht S, Leucht C, Huhn M, et al. Sixty years of placebo-controlled antipsychotic drug trials in acute schizophrenia: systematic review, bayesian meta-analysis, andmeta-regression of efficacy predictors.AmJ Psychiatry. 2017;174(10): 927-942. doi:10.1176/appi.ajp.2017.16121358; 2009;

60. Nakamura M, Ogasa M, Guarino J, Phillips D, Severs $\mathrm{J}$, Cucchiaro J, et al. Lurasidone in the treatment of acute schizophrenia: a double-blind, placebocontrolled trial. Journal of Clinical Psychiatry. 2009;70(6):829.

61. Study115. Center for Drug Evaluation and Research. Approval package for application number 20-825. Medical review(s). Cited by: Leucht S, Leucht C, Huhn M, et al Sixty years of placebo-controlled antipsychotic drug trials in acute schizophrenia: systematic review, bayesian meta-analysis, and meta-regression of efficacy predictors Am J Psychiatry 2017;174(10):927-942 doi:101176/appiajp201716121358. 2000;

62. Beasley CM, Sanger T, Satterlee W, Tollefson G, Tran $\mathrm{P}$, Hamilton S. Olanzapine versus placebo: results of a double-blind, fixed-dose olanzapine trial. Psychopharmacology. 1996;124(1-2):159-67.

63. Lindenmayer J-P, Brown D, Liu S, Brecher M, Meulien D. The efficacy and tolerability of once-daily extended release quetiapine fumarate in hospitalized patients with acute schizophrenia: a 6-week ran- 
domized, double-blind, placebo-controlled study.800 Psychopharmacology Bulletin. 2008;41(3):11-35.

64. Schmidt ME, Kent JM, Daly E, Janssens L, Van Osse-802 laer N, Hüsken G, et al. A double-blind, random-803 ized, placebo-controlled study with JNJ-37822681, ${ }_{804}$ a novel, highly selective, fast dissociating D2 recep- ${ }_{805}$ tor antagonist in the treatment of acute exacerbation ${ }_{806}$ of schizophrenia. European Neuropsychopharmacology. 2012;22(10):721-33.

65. Meltzer HY, Arvanitis L, Bauer D, Rein W, Group M-TS. Placebo-controlled evaluation of four novel compounds for the treatment of schizophrenia and schizoaffective disorder. American Journal of Psychiatry. 2004;161(6):975-84.

66. Coppola D, Melkote R, Lannie C, Singh J, Nuamah I, Gopal S, et al. Efficacy and Safety of Paliperidone Extended Release $1.5 \mathrm{mg} /$ day - A Doubleblind, Placebo-and Active-Controlled, Study in the Treatment of Patients with Schizophrenia. Psychopharmacology Bulletin. 2011;44(2):54.

67. Chouinard G, Jones B, Remington G, Bloom D, Addington D, MacEwan GW, et al. A Canadian multicenter placebo-controlled study of fixed doses of risperidone and haloperidol in the treatment of chronic schizophrenic patients. Journal of Clinical Psychopharmacology. 1993;13(1):25-40.

68. Senn S. Seven myths of randomisation in clinical trials. Statistics in Medicine. 2013;32(9):1439-50.

69. Leucht S, Davis JM. Enthusiasm and skepticism about using national registers to analyze psychotropic drug outcomes. JAMA Psychiatry. 2018;75(4):314-5.

70. Kubo K, Fleischhacker W, Suzuki T, Yasui-Furukori N, Mimura M, Uchida H. Placebo effects in adult and adolescent patients with schizophrenia: combined analysis of nine RCT s. Acta Psychiatrica Scandinavica. 2018;139(2):108-16.

71. Hróbjartsson A, Gøtzsche PC. Is the placebo powerless? An analysis of clinical trials comparing placebo with no treatment. New England Journal of Medicine. 2001;344(21):1594-602.

72. Senn S. Applying results of randomised trials to patients: $\mathrm{N}$ of 1 trials are needed. British Medical Journal. 1998;317(7157):537.

73. Wang R, Lagakos SW, Ware JH, Hunter DJ, Drazen JM. Statistics in medicine-reporting of subgroup analyses in clinical trials. New England Journal of
Medicine. 2007;357(21):2189-94.

74. Araujo A, Julious S, Senn S. Understanding variation in sets of N-of-1 trials. PLoS One. 2016;11(12):e0167167.

75. Joyce D, Tracy D, Shergill S. Are we failing clinical trials? A case for strong aggregate outcomes. Psychological Medicine. 2018;48(2):177-86.

76. Gonzalez A, Cox D. Interpretation of interaction: A review. Ann Appl Stat. 2007;1(2):371-85. 